\title{
A produção do espaço urbano nos diferentes padrões de acumulação: o fordismo e a acumulação flexível em perspectiva
}

La production d'un espace urbain dans les différents motifs d'accumulation: le fordisme et l'accumulation flexible en perspective

La producción del espacio urbano en los diferentes estándares de acumulación: fordismo y acumulación flexible en perspectiva

The production of urban space in the different patterns of accumulation: fordism and flexible accumulation in perspective

\section{Samarane Fonseca de Souza Barros}

\section{(2) OpenEdition}

Journals

Electronic version

URL: http://journals.openedition.org/espacoeconomia/5841

DOI: 10.4000/espacoeconomia.5841

ISSN: 2317-7837

\section{Publisher}

Núcleo de Pesquisa Espaço \& Economia

Electronic reference

Samarane Fonseca de Souza Barros, «A produção do espaço urbano nos diferentes padrões de acumulação: o fordismo e a acumulação flexível em perspectiva », Espaço e Economia [Online], 14 | 2019, Online since 11 August 2019, connection on 04 September 2019. URL : http:// journals.openedition.org/espacoeconomia/5841; DOI : 10.4000/espacoeconomia.5841

This text was automatically generated on 4 September 2019.

(c) NUPEE 


\title{
A produção do espaço urbano nos diferentes padrões de acumulação: o fordismo e a acumulação flexível em perspectiva
}

\author{
La production d'un espace urbain dans les différents motifs d'accumulation: le \\ fordisme et l'accumulation flexible en perspective \\ La producción del espacio urbano en los diferentes estándares de acumulación: \\ fordismo y acumulación flexible en perspectiva \\ The production of urban space in the different patterns of accumulation: \\ fordism and flexible accumulation in perspective
}

\section{Samarane Fonseca de Souza Barros}

\section{INTRODUÇÃO}

1 Os modos de produção sempre foram importantes para designar a produção do espaço e, em especial, os moldes da urbanização. Considerando a cidade o lócus de produção, circulação e consumo das mercadorias, ela é o signo do padrão capitalista construída por agentes diversos.

2 A produção do espaço e a reprodução da vida cotidiana estão intrínsecas aos processos de produção e realização das mercadorias, logo, os padrões de acumulação do capital apresentam uma importante variável espacial. No espaço urbano, sobretudo, é onde as grandes relações capitalistas e de trabalho se concretizam, sendo, portanto, causa e consequência dos processos de luta de classes e divisão social do trabalho.

3 Dadas as mudanças no paradigma capitalista e as reestruturações produtivas ocorridas a partir da década de 1970 os espaços intra e interurbano das cidades também se reestruturaram, visto que grande parte das transformações nos moldes de produção 
engendraram mudanças espaciais. Vale salientar que esta escala temporal abrange o grande ciclo de reprodução do capital, sabendo que não é linear e tampouco coincidente em todas as áreas do globo, inclusive, porque em alguns países de industrialização tardia, como o caso brasileiro, o fordismo não se expressou de maneira tão efetiva e a reestruturação produtiva ocorreu com mais vigor a partir da década de 1990.

4 Isto posto, o artigo que segue busca apresentar os padrões de acumulação fordista e de acumulação flexível e as suas respectivas implicações espaciais, estando dividido em duas outras partes, além desta introdução e das considerações finais: a primeira vislumbrando a apresentação dos padrões de acumulação e a segunda apresentando as transformações na rede urbana brasileira a partir das mudanças econômicas, dando foco para a ascensão e os papéis que às cidades médias assumiram neste contexto.

\section{1) Fordismo e acumulação flexível}

5 As mudanças no capitalismo no fim do século XX habitaram inúmeras esferas da vida socioeconômica, bem como exprimiram suas marcas reestruturantes nos processos trabalhistas, hábitos de consumo e padrões geográficos e geopolíticos. As grandes mudanças ocorridas a partir da primeira recessão econômica na década de 1970 marcou a "transição no regime de acumulação e no modo de regulamentação social e política a ele associado" (HARVEY, 1992, p. 117). Os regimes de acumulação necessitam de normas para o seu pleno funcionamento, ou seja, para alinhar os comportamentos individuais ao processo de reprodução do capital, sendo, portanto, essa materialização do regime de acumulação conhecido como modo de regulamentação (LIPIETZ, 1986 apud HARVEY, 1992, p. 117).

6 O período pós-Guerra até meados da década de 1970 teve como padrão de acumulação e bases de controle político, econômico e social o modo de regulamentação fordistakeynesiano, com subsídios e contratos rígidos e burocratas. A crise, a partir de 1973, marcou um período de mudanças rápidas, fluidas e incertas que previam tornar os processos de trabalho e mercado mais flexíveis, inaugurando o padrão de acumulação que Harvey (1992) designou como acumulação flexível. As transformações produtivas e de acumulação vêm para favorecer a reprodução do capital, considerando que a dinâmica do universo capitalista "é regida pela riqueza acumulada que insaciavelmente precisa crescer" (MARTINS, 1982, p. 17).

7 Adiante, serão explorados ambos os padrões de acumulação demonstrando as principais características e, sobretudo, sinalizando que os períodos de recessão econômica significam reestruturações geográficas, principalmente, no que tange a urbanização e as cidades, por estas serem fundamentais para as condições de produção e reprodução do capital.

\section{1) Fordismo}

8 Ainda em 1914, Henry Ford introduziu em suas fábricas de automóveis a rotina de 8 horas e 5 dólares como recompensa aos trabalhadores, porém, a difusão e consolidação do fordismo enquanto sistema produtivo e padrão de acumulação foi posterior - e mais complexo - que as ideias de Ford. 
O empresário delimitou bem a divisão do trabalho no interior da fábrica, demonstrando que as tarefas deveriam seguir padrões rigorosos de tempo e movimento, sendo, por isso, o principal avanço técnico do período a esteira. A divisão hierárquica do trabalho, bem como a separação entre gerência e produção possibilitaram o aumento significativo da produtividade, alcançando a produção em massa. Vale salientar que produção em massa significa consumo em massa, provendo indícios para um novo tipo de trabalhador e de sociedade. 0 novo tipo de sociedade, baseado no poder corporativo, permitiria que o trabalhador adquirisse a disciplina necessária para aumento da produção e que ele tivesse tempo e renda para consumir os produtos que vinham sendo produzidos em grandes lotes. Além disso, o novo homem para Ford, deveria ter probidade moral, familiar, consumo prudente e racional (HARVEY, 1992, p. 122).

Todavia, nem mesmo o corporativismo e regulamentação de Ford foram suficientes para burlar a grande depressão econômica de 1929, "foi necessário o New Deal de Roosevelt para salvar o capitalismo - fazendo, através da intervenção do Estado, o que Ford tentara fazer sozinho" (HARVEY, 1992, p. 122). Porém, o longo período de expansão do pós-Guerra foi propício para a demanda efetiva dos produtos de Ford, principalmente por causa das marcas precedentes de suburbanização e desconcentração da população e da indústria.

11 O sistema fordista, destarte, começou a se consolidar após 1945, envolvendo decisões corporativas, institucionais e estatais, pois era preciso novas concepções de uso do poder para a sociedade capitalista manter a sua reprodução. Era preciso, tal como proposto por Keynes, formular um conjunto de estratégias administrativas científicas e de poderes estatais que estabilizassem o capitalismo (HARVEY, 1992, p. 124). A maturidade, porém, do papel que o Estado deveria assumir só veio a partir do pós-guerra, formando as bases para o período de expansão. Alinhado a perspectiva keynesiana, o fordismo levou o capitalismo a assumir notáveis taxas nos países mais abastados, bem como propiciou a consolidação do Estado de bem-estar social.

Em síntese, o padrão fordista de produção se baseava em:

Grandes lotes (produção em massa); movimentos rápidos, eficiência medida pela rapidez dos movimentos singulares dos homens [...] e máquinas universais; estoques intermediários como recurso para maximizar o rendimento de cada máquina e de cada trabalhador; fábricas organizadas em seções fixas (tornearia, usinagem, etc.) cada uma reunindo máquinas e processos similares (tornos, fresas, pintura) (FERRARI, 2005, p. 28).

13 O crescimento e consolidação do capitalismo apoiado em bases fordistas dependeu de uma série de compromissos por parte dos agentes envolvidos no processo. 0 Estado assumiu novos papéis e poderes institucionais, o capital corporativo se ajustou para seguir com mais suavidade e o trabalho organizado também ganhou novos moldes para o aumento da produtividade. Sendo assim, a principal tríade do sucesso do sistema fordista se formou envolta do grande Estado, do grande Capital e do trabalho organizado.

O poder corporativo assegurava o crescimento de investimentos e aumento da produtividade, além de elevar os padrões de vida e taxas de lucro. A administração científica foi o marco da racionalidade corporativa burocrática, tornando as decisões empresariais hegemônicas na definição do crescimento da produção e consumo em massa levando que, por conseguinte, o Estado e os trabalhadores fizessem as suas respectivas partes para manter constante a demanda e os níveis do lucro capitalista.

15 Devido à grande e organizada força dos trabalhadores, o momento foi importante para a consolidação do poder sindical que, em muito, se conciliava as corporações para negócios 
que envolviam aumento de produtividade e ganhos de salário, o suficiente para manter os empregados submissos as forças hegemônicas.

16 O Estado se esforçava para investimento em infraestruturas territoriais e capitais fixos, controle dos ciclos econômicos e seguridade social para as pessoas, isto é, tudo que mantivesse o clima favorável de negócios intrínseco ao Estado de bem-estar social do regime fordista-keynesiano.

17 Harvey (1992, p. 131) acrescenta que o fordismo do pós-guerra deve ser compreendido como um modo de vida total, pois a produção em massa significou a padronização do produto e do consumo em massa, implicando na mercadificação da cultura. A estética do modernismo, principalmente por causa da funcionalidade e eficiência, dava ao sistema a coerência necessária para a difusão da consciência de uma democracia econômica de massa. A vida social, de acordo com Chesnais (2000, p.9), "em quase todas as suas determinações tende a sofrer influências daquilo que Marx designa como a forma mais impetuosa de fetichismo".

18 A mercadoria passou a mediar as relações sociais, à medida que os homens

se relacionam como se fossem objetos, como se fossem coisas determinadas por um mundo social objetivado. Nesse caso, os próprios critérios do relacionamento são coisificados, como são coisificados tanto a atividade humana quanto os seus resultados. A perspectiva do homem comum também está marcada pela coisificação, pois essa é uma maneira historicamente necessária da sociedade capitalista se ver e se interpretar (MARTINS, 1982, p. 57).

19 A esfera e o mercado internacional também permearam o fordismo. A abertura dos investimentos estrangeiros e do comércio permitiu que o excedente estadunidense fosse absorvido em outras áreas, ao passo que o mercado global dos produtos em massa foi se consolidando, imprimindo um aspecto global ao capitalismo. Contudo, o aspecto integrador e global do capital é paradoxal, posto que é um quadro em que "a relação social dos produtores no conjunto do processo do trabalho aparece mais uma vez e com uma força renovada 'como uma relação social externa a eles, uma relação entre objetos"' (CHESNAIS, 2000, p. 9).

20 A hegemonia geopolítica e econômica dos Estados Unidos era inquestionável, sobretudo, a partir de 1944 quando o dólar foi transformado em moeda-reserva mundial. o país era o centro capitalista fornecedor de crédito em troca da abertura dos mercados as grandes corporações. Além da esfera econômica, o America way of life uniformizava cada vez mais as culturas e impunha, em grande medida, a ordem global sobre a local. Os Estados Unidos, portanto, foram os responsáveis pela disseminação internacional do fordismo sob a égide de um sistema de alianças militares e relações de poder.

21 Entretanto, nem todos foram atingidos pelas benfeitorias fordistas. As desigualdades são intrínsecas ao desenvolvimento do capitalismo, se produzindo no processo funcional da sociedade capitalista. Por ela ser parte do sistema e parte fundamental para a sua reprodução, os detentores dos meios de produção - e do capital - são interessados em manter a desigualdade social. A especialização da mão de obra branca e masculina significava uma rigidez nos mercados de trabalho, levando os sindicatos a serem desmobilizados e atacados pelas minorias, sobretudo, por eles [os sindicatos] estarem mais vinculados a grupos de interesses específicos do que a objetivos gerais.

22 O Estado também passou a se enfraquecer diante do descontentamento de ordens civis. À medida que provinha de seguridade social para a população e construía capital fixo, o 
custo passou a ser maior que a receita, inviabilizando a manutenção do Estado de bemestar social keynesiano.

23 A desigualdade também se exprimiu na dimensão espacial, visto que os países subdesenvolvidos não foram agraciados pela modernidade fordista, apenas sofreram mais com a destruição e opressão das culturas locais. 0 desenvolvimento geográfico desigual é ao mesmo tempo produto e premissa ao desenvolvimento capitalista, como visto em Smith (1988, p. 221):

Como produto, o padrão é altamente visível na paisagem do capitalismo, tal como a diferença entre espaços desenvolvidos e subdesenvolvidos em diferentes escalas: $o$ mundo desenvolvido e o subdesenvolvido, as regiões desenvolvidas e as regiões em declínio, os subúrbios e o centro da cidade. Como premissa da expansão capitalista, o desenvolvimento desigual [...] é a desigualdade social estampada na paisagem geográfica e é simultaneamente a exploração daquela desigualdade geográfica para certos fins sociais determinados.

24 A produção ocorre, principalmente, na cidade, levando-a a assumir também as principais implicações - positivas e negativas - do processo capitalista. Porém, de acordo com Lefebvre (1972, p. 52), a cidade possui duas acepções do termo de produção, pois

sendo também ela obra, é o lugar onde produzem obras diversas, incluindo o que dá sentido à produção: necessidades e satisfações. Igualmente constitui o lugar onde produzem e trocam os bens, onde são consumidos. Nela se conjugam estas realidades, estas modalidades do produzir, umas imediatas outras mediatas (indiretas). Esta unidade, de que é o suporte social, de que é o sujeito, unidade que era abstrata e intemporal, recebe da cidade concretização e inserção no tempo.

O fordismo em muito se associou ao avanço da industrialização de maneira aglomerada em polos de crescimento e desenvolvimento. Por consequência, os tipos de cidade que emergiram no fordismo também respondem por grandes aglomerações urbanas, econômicas e humanas. $O$ processo de produção é indissociável do processo de produção do espaço, como sugere Santos (1978, p. 163), logo, se as relações nesse período ocorreram, principalmente, no meio urbano, o processo de produção é, ao mesmo tempo, produtor do espaço urbano. De acordo com Sposito (2004, p. 51), a produção do espaço urbano é o conjunto de ações e ideias que põe em movimento a sociedade e "por meio desse movimento e a ele dando suporte, cria e recria o mundo urbano e as cidades".

o paradigma fordista era baseado na lógica industrial em que o capital era concentrado em mercados nacionais devido, entre outras coisas, a centralização do poder corporativo. A lógica rígida do sistema buscava economias de escala a partir do aumento das dimensões fabris e, portanto, engendrava o desenvolvimento de grandes cidades que polarizavam regiões a partir do fornecimento de serviços.

27 A rigidez do sistema fordista e a necessidade de aglomeração industrial propiciaram uma urbanização, tipicamente, metropolitana cujo Estado era o provedor dos bens de consumo coletivo na esfera da reprodução (CASTELLS, 1983) e havia a estabilidade do setor industrial na produção, no concernente a grande empregabilidade demandada. Em síntese, a metrópole fordista é marcada pela industrialização em larga escala associada a atuação de um Estado baseado em princípios keynesianos no que diz respeito ao bemestar social.

28 O planejamento das infraestruturas urbanas, no contexto fordista, era destinado a satisfação das grandes corporações, então eram levantadas para atender ao mercado padronizado dos produtos em massa. Além disso, os grandes pátios industriais agitavam o mercado imobiliário na criação de vilas e bairros operários, engendrando uma estrutura 
urbana bem hierárquica para as cidades tipicamente fordistas. Além disso, muitas indústrias também foram responsáveis pela criação de bairros para abrigar a mão de obra, sendo um importante agente na morfologia das cidades.

29 Em suma, as cidades fordistas eram burocráticas e inflexíveis, desenroladas em torno de áreas industrializadas, favorecendo o trânsito entre os operários e, nesta direção, as grandes aglomerações urbanas. Além disso, possuíam uma hierarquia socioespacial bem delimitada entre centro e periferia em que este primeiro é o grande influenciador e abriga o poder político-administrativo e as matrizes das grandes economias.

\section{2) Acumulação flexível}

30 O período entre 1966 e 1973 evidenciou as falhas do sistema fordista para as contradições intrínsecas ao capitalismo, sobretudo, no que diz respeito a rigidez dos processos nos investimentos, nos mercados devido a produção em massa e nos contratos de trabalho. As tentativas de superar os problemas eram em vão, considerando a forte articulação entre o grande trabalho, a grande empresa e o grande Estado - sendo que este último estava com cada vez mais dificuldade de se manter. Nas condições gerais de deflação que assolavam a realidade capitalista, as corporações passaram a considerar mudanças tecnológicas, busca por novas linhas de produto e nichos de mercado, a dispersão geográfica para zonas sem tradição trabalhista e medidas para acelerar o tempo de giro do capital como estratégias primeiras para a manutenção da reprodução do sistema (HARVEY, 1992, p. 140).

31 As décadas de 1970 e 1980 foram marcadas por reestruturações econômicas, políticas e sociais. As alterações na organização da produção e do consumo e a instabilidade na vida social e política marcaram a transição para um novo regime de acumulação associado a um sistema de regulação, ao qual Harvey (1992) designou acumulação flexível.

32 A acumulação flexível se opõe ao fordismo, principalmente, no que tange a rigidez. 0 novo padrão de acumulação é baseado na flexibilidade e fluidez dos contratos trabalhistas, mercados e padrões de consumo. Marca a aparição de novos setores de produção, novas formas de serviços financeiros, e a inovação tecnológica e organizacional dos mercados. Ademais, significou um grande incremento dos empregos no setor de serviço e a industrialização de áreas até então não convencionais. Ainda, de acordo com Harvey (1992, p. 140), o período marca a compressão do espaço-tempo, isto é,

os horizontes temporais da tomada de decisões privada e pública se estreitaram, enquanto a comunicação via satélite e a queda dos custos de transporte possibilitaram cada vez mais a difusão imediata dessas decisões num espaço cada vez mais amplo e variegado.

33 A flexibilidade e a mobilidade do novo padrão permitiram a maior pressão por parte dos empregadores sobre uma força de trabalho enfraquecida e pouco organizada. Houve a recessão do poder sindical, bem como um aumento significativo do desemprego estrutural e diminuição dos salários reais. A reestruturação do mercado de trabalho só foi favorável aos patrões que aproveitaram da volatilidade do mercado e do grande número de desempregados para impor regimes e contratos mais flexíveis. Para o trabalhador, isto significou redução nos empregos regulares e aumento das terceirizações, subempregos e, inclusive, dos mercados informais. A tendência das empresas, bem como as japonesas, é cada vez mais contratar forças de trabalho facilmente demitíveis no lugar de trabalhadores regulares. Os efeitos agregados também são ruins, uma vez que os seguros os direitos de pensão e os níveis salariais também reduziram. 
34 A organização industrial também sofreu modificações. Pequenas e médias empresas surgiram e retomaram sistemas antigos baseados em paternalismos, bem como novas formas emergiram baseadas nos avanços técnicos e de mão de obra muito especializada. De acordo com Martins (1982, p. 16), "o cientista só deixa de ser doido quando trabalha para o capital (...) para atender a demanda da reprodução do dinheiro pelo dinheiro". As transformações na organização da produção e a ascensão de novas técnicas "puseram em risco os negócios da organização tradicional, espalhando uma onda de bancarrotas, fechamento de fábrica, desindustrialização (...)" (HARVEY, 1992, p. 146).

35 As economias de escalas propostas pelo sistema fordista massificado foram substituídas pela capacidade das pequenas manufaturas de produzirem bens variados a baixos custos e sob demanda. Junto as subcontratações, a produção em pequenos lotes propiciou a superação da rigidez fordista para atender as demandas do mercado que, cada vez mais, são mutáveis. A crise das grandes aglomerações estava inaugurada.

36 A produção flexível, ainda, permitia o acelerado ritmo de inovações dos produtos e atendia os mercados muito especializados. Os estoques fordistas deram espaço a um gerenciamento just in time que reduzia grande parte dos insumos para manter a produção fluindo. Os produtos tornaram-se mais efêmeros, diferentes e a busca pela originalidade tornou-se status. As mudanças no padrão de consumo aliadas as mudanças na produção justificam o aumento significativo dos empregados no setor de serviços (HARVEY, 1992, p. 148).

37 Porém, toda a mobilidade da produção não esgotou o papel das grandes corporações que em um ambiente competitivo e de tomadas de decisões rápidas ainda saíam na frente dos pequenos negócios. A reprodução do capitalismo sob a ótica flexível ocorre, cada vez mais, a partir das fusões e aquisições de firmas e da mobilidade geográfica do capital, mercadorias e pessoas.

38 Devido aos avanços técnicos, o conhecimento científico ganhou ainda mais destaque e vantagens competitivas, mercantilizando o saber. A produção organizada do saber científico, assim como a valorização da imagem corporativa e do produto passaram a ganhar destaque no tocante a agregação de valor a um determinado produto.

39 Um eixo emblemático do novo padrão de acumulação é o serviço financeiro, o qual se tornou tão complexo que foge da explicação da maioria das pessoas (HARVEY, 1992, p. 152). A desregulamentação e a formação de um mercado de ações global completamente integrado pelas facilidades da comunicação instantânea coadjuvaram para a formação de um sistema financeiro mundial de dinheiro e de crédito. Todavia, "atrás da expressão neutra da 'mundialização da economia' e seu corolário já mais explícito da 'vitória do mercado', esconde-se um modo específico de funcionamento e de dominação política e social do capitalismo" (CHESNAIS, 2000, p. 7).

40 A importância do sistema financeiro para a acumulação flexível - e vice versa - vai ao encontro das possibilidades de transição do capital sem maiores fronteiras de tempo e espaço, levando o padrão de acumulação a procurar o sistema financeiro mundial como coordenador. $\mathrm{O}$ modo de regulamentação, neste sentido, passou a ser o neoliberalismo, sendo conivente com a nova realidade financeira.

41 O Estado, portanto, também se ressignificou. Ele se encontra em uma posição paradoxal, na qual deve manter os interesses da nação e regularizar o capital corporativo, assim como manter uma atmosfera favorável de negócios para atração do capital financeiro transnacional. 
Segundo Brenner (1998, p. 18) as alterações nas instituições e papéis do Estado não significam um declínio do mesmo, mas sim uma

estratégia geográfica de acumulação para promover e regular a restruturação nas regiões urbanas de maior importância. De fato, estratégias neoliberais recentes para promover mercados desregulamentados e a mobilidade do capital, necessariamente pressupõem a construção de novos espaços locais e regionais de produção e regulação no qual o momento de arranjo geográfico do capital pode ser assegurado. Esta tensão entre a desregulamentação (que favorece o momento de mobilidade geográfica do capital) e a r e-regulamentação (que privilegia o momento de arranjo geográfico do capital) pode ser vista como uma das contradições insolúveis do neoliberalismo enquanto estratégia de acumulação.

43 Então, as formas espaciais da acumulação flexível, sobretudo as cidades, muito se diferenciam das estruturas fordistas, apesar de continuarem sendo os centros de poder e decisão. Isto porque o espaço urbano "não se refere somente a uma dada configuração espacial, mas também à forma como estão estruturadas as relações de produção, numa dada conjuntura de um modo de produção." (GOHN, 1982, p. 20).

De acordo com Ferrari (2005, p. 18), as cidades contemporâneas são baseadas nas relações trabalhistas exploratórias, sendo lugares onde as pessoas alienam a força de trabalho em prol de um capital cada vez mais transnacional. A autora acrescenta que o espaço urbano flexível é marcado por

relações materializadas pela imposição de uma apologia do lugar, pela seleção de vocações regionais, pelas conexões em um presumido tempo real aos fluxos globais e pelas políticas - identificadas como públicas - que se propõem a lidar microscopicamente com os efeitos do desemprego e da precarização do trabalho promovidos pela dinâmica atual da reprodução geral do capital (FERRARI, 2005, p. 19).

45 Em linhas gerais, as cidades pós fordistas deixam de lado as grandes chaminés das indústrias devido ao avanço das técnicas e tecnologias e a maior flexibilidade do padrão de acumulação. Não há mais a necessidade de se aglomerar, devido a maior dispersão da produtividade e os avanços dos meios de transporte e comunicação. Devido a essas facilidades, o tecido intraurbano também se reestruturou, levando a muitas cidades a assumirem uma multicentralidade. As alterações da cidade fordista para a pós-fordista são bem significativas em função, sobretudo, da reestruturação produtiva a qual o Brasil e o mundo - passou a partir da década de 1970, como será explorado adiante.

\section{2) Reestruturação produtiva e mudanças na rede urbana brasileira: a ascensão das cidades médias}

A urbanização é um processo pelo qual pode ser compreendido a partir da mudança produtiva e social ao longo do tempo e seus desdobramentos espaciais. À medida que o processo produtivo se reestrutura o espaço urbano é também modificado nas mais diversas dimensões escalares devido a ação de agentes políticos, econômicos e sociais.

No Brasil, a reestruturação produtiva teve início na década de 1970 com a crise do sistema fordista e no desenvolvimento baseado na substituição das importações, se intensificando na década de 1990 com o avanço neoliberal e abertura econômica que desencadearam mudanças no processo produtivo e organização do espaço (GOMES, 2011). A reestruturação do capitalismo é um processo socioespacial (GOTTDIENER, 1993), pois é consequência do processo capitalista que implica transformações na sociedade e no 
espaço, principalmente através da desconcentração, neste momento pós-fordista. A reestruturação produtiva, portanto, para além de alterações no sistema organizacional do capitalismo engendra mudanças nas mais diferentes escalas espaciais e sociais.

48 A escala aqui priorizada para compreensão das reestruturações produtivas e geográficas será a da rede urbana, pois ela se complexificou ao passo que as cidades passaram a se inserir de formas diferentes, alterando os seus respectivos tamanhos e papéis, bem como as interações e articulações espaciais dos centros urbanos. Rede urbana é aqui compreendida de acordo com Corrêa (2006) enquanto um conjunto de centros articulados funcionalmente, tendo sua complexidade relacionada a combinação de características, como tamanho dos centros, densidade das relações no espaço regional, as funções que desempenham, o alcance regional, dentre outras.

49 Segundo Corrêa (2001) a partir da década de 1970 a rede urbana brasileira sofreu inúmeras transformações em função das mudanças ocorridas na organização socioespacial. Dentre elas, destaca-se a ampliação, diversificação e desconcentração das atividades industriais, a modernização do campo, as inovações industriais junto ao setor de comércio e serviços, ampliação da base técnica associada aos meios de transporte e comunicação, a fusão e constituição de grandes complexos empresariais, a incorporação de novas áreas ao processo produtivo global, os novos padrões de mobilidade das pessoas e do capital, o aumento quanti-qualitativo da urbanização, a crescente estratificação social e o aumento do consumo. Em suma, as mudanças na organização socioespacial vão ao encontro das demandas do novo padrão de acumulação flexível, associado ao capital neoliberal e global, como já citado.

50 Então, com as mudanças nas estruturas capitalistas e a ressignificação nos conteúdos e formas de uso do espaço, a rede urbana se reestruturou a partir da redefinição dos papéis das cidades dos mais variados tamanhos (SANTOS, 1994). Corrêa (2001; 2001a) elucida que as mudanças a partir de 1970 propiciaram uma maior articulação entre os centros urbanos devido a criação de novos núcleos e complexificação nas suas funções, ampliando as interações espaciais que eram, predominantemente, regionais. Concordando com Bessa (2005, p. 269) "a rede urbana reflete e reforça as características dos contextos políticos, econômicos e socioculturais do território, sendo, portanto, uma dimensão socioespacial, ou seja, um elemento integrante da própria realidade em sua complexidade".

51 Sposito (2001) alinha as mudanças na urbanização brasileira as mudanças nos padrões de industrialização, considerando que quando se analisa o processo de urbanização em sua dimensão histórica o principal vetor de sua redefinição é a industrialização por ocupar, em um primeiro momento, a centralidade no modo capitalista de produção. Para tal, a autora considera dois aspectos fundamentais para compreensão da rede urbana e das diferentes cidades que a compõem: a complexidade na divisão social do trabalho e, por conseguinte, a divisão territorial do trabalho e o crescente papel do consumo da produção industrial que gera novos núcleos urbanos e consolida os já existentes (SPOSITO, 2001, p. 618).

52 A rede urbana brasileira foi se modificando para atender as demandas nacionais e, $\grave{a}$ posteriori, internacionais, se integrando de maneira orgânica ao modo capitalista de produção. Para fins didáticos, Sposito (2001) reconhece três momentos no processo da constituição da rede urbana brasileira: a) de 1930 a 1955 em que o incremento da industrialização engendrou o aumento no número de cidades, principalmente, na porção centro-sul brasileira, engendrando uma rede urbana primaz em formato de arquipélago com poucas e concentradas cidades grandes e muitas cidades pequenas; b) de 1955 a 
meados da década de 1980 em que o Brasil passa a assumir, devido a alianças políticas, novos papéis na divisão internacional do trabalho e a produção começa a se interiorizar pelo território, aumentando em número e tamanho as cidades e as levando para dentro do país, estruturando de maneira mais equilibrada a rede urbana, mas ainda sem atingir um padrão rank size; c) por fim, de 1985 adiante que respondendo pela crise da década de 1970 e pelas mudanças proporcionadas pela abertura comercial da década de 1990 acentuou a reestruturação e flexibilização do sistema produtivo, bem como uma maior financeirização das grandes metrópoles e ascensão de núcleos urbanos não metropolitanos enquanto relais no sistema de cidades.

53 Nesse contexto de mudanças na rede urbana e mudanças nos papéis e interações das cidades, as cidades médias passaram a se inserir de diferentes maneiras, uma vez que devido a interiorização da produção, muitas delas se dinamizaram e tornaram-se pontos relevantes na rede urbana.

De acordo com Bessa (2005, p. 270), as cidades médias assumem dinamismo na urbanização brasileira, principalmente, quando atingidas pela expansão do meio técnico científico-informacional, uma vez que tiveram seus territórios complexificados e passaram a gerar fluxos materiais e imateriais, assumindo atividades econômicas antes restritas aos espaços metropolitanos. Nesta direção, as cidades médias cresceram demograficamente (ANDRADE; SERRA, 2001) e assumiram importante função de equilíbrio na rede urbana brasileira, sobretudo, por coadjuvarem na redução dos fluxos migratórios rumo às grandes cidades.

Contudo, para além do debate demográfico, as cidades médias são aqui compreendidas considerando a funcionalidade delas nas redes e regiões as quais estão alocadas, bem como o seu dinamismo econômico e capacidade de intermediação e polarização para com outros núcleos urbanos. Amorim Filho (1984) e Sposito (2001) destacaram o papel de intermediação destas cidades, colocando que elas têm uma vida de relações tanto com cidades de mesmo porte e de porte superior, como com cidades menores e áreas rurais que estão em sua área de polarização.

56 As relações das cidades médias nas mais variadas dimensões escalares e, por conseguinte, a ampliação de seus papéis frente a rede urbana brasileira, foram possibilitadas pelos avanços nas tecnologias de transporte e comunicação que também propiciaram a maior fluidez dos territórios. Sposito (2001, p. 638) levanta o par das continuidades e descontinuidades territoriais para demonstrar que as cidades médias transitam em diferentes segmentos da rede urbana, incrementando a importância delas para a realidade urbana brasileira. Em síntese, Bessa (2005, p. 275) coloca

Assim, o contexto de relações das cidades médias é definido em duas escalas: uma horizontalizada, a partir da estruturação de uma área contínua; e, outra, verticalizada, fundada sobre múltiplas redes que desenham relações com cidades hierarquicamente superiores e também com cidades de mesma importância, assim como uma rede de relações entre regiões, sugerindo a conformação de redes regionais (...).

$57 \mathrm{Na}$ atual fase do capitalismo de expansão das técnicas e aumento dos fluxos de pessoas e capitais, as cidades médias respondem enquanto nós na complexa divisão social e territorial do trabalho inerente a rede urbana, por isso demandam que sejam analisadas cada uma com sua particularidade, apesar de apresentarem características semelhantes que as classificam como médias. 

cidades médias brasileiras, devido a, sobremaneira, três fatores principais: a reestruturação produtiva mais incidente, a abertura comercial e o redimensionamento do Estado. Fatores tais tratados de maneira detalhada adiante.

\section{1) A década de 1990 e o novo papel das cidades médias no Brasil}

59 A década de 1970 testemunhou no mundo maiores preocupações com o equilíbrio urbano-regional, sobretudo, a partir de núcleos intermediários. O caso mais emblemático foi o Aménagement du Territoire enquanto planificação para solucionar o caso de Paris e o deserto francês (AMORIM FILHO; SERRA, 2001).

No Brasil, na mesma década, os Planos Nacionais de Desenvolvimento (PND) também se preocupavam com a integração nacional, sendo que o II PND explicitou a importância das cidades médias afim de minimizar os impactos das economias de aglomeração. 0 Programa Nacional de Apoio às capitais e cidades de porte médio (PNCCPM) integrou o II PND e tinha o intuito de agir na melhor distribuição e relacionamento entre as cidades, principalmente, ao considerar as cidades de porte médio enquanto centrais na disseminação da economia e da própria urbanização. 0 plano, apesar de defender o maior equilíbrio e ocupação do território no interior do país, seguiu reproduzindo, internamente, as desigualdades inter-regionais, sobretudo, ao considerar as áreas menos abastadas altamente dependentes das outras no que diz respeito a economia, ciência e tecnologia.

61 Na década de 1980 o que se observou no Brasil foram políticas de urbanização que vislumbravam mais as escalas macrorregionais devido a priorização do governo a política monetária e a contenção da crise fiscal, além da diminuição das migrações inter-regionais que reduziu as políticas anteriores da contenção dos fluxos migratórios aos grandes centros urbanos.

62 A retomada pelo interesse às cidades médias marca a década de 1990 de maneira diferenciada, pois, aumenta-se a produção acadêmica e científica, mas diminui o papel do Estado enquanto promotor das mudanças na rede urbana. Este aumento de interesse pode ser associado, principalmente, a própria ampliação dos papéis destas cidades relacionadas a reestruturação produtiva e a abertura comercial. Em suma, há três fenômenos que não são neutros que justificam a retomada do interesse pelas cidades médias em uma perspectiva de "desconcentração concentrada": reestruturação produtiva, abertura comercial e redimensionamento do Estado (AMORIM FILHO; SERRA, 2001, p. 22).

63 A reestruturação produtiva marcada pelas revoluções tecnológicas e científicas influenciaram a desconcentração urbana, ao passo que com o desenvolvimento das tecnologias de transporte e comunicação possibilitaram reduzir os custos locacionais. Ademais, "esse efeito sobre os modelos locacionais tenderia a intensificar-se com o avanço do novo paradigma produtivo (centrado na microeletrônica e na informação) sobre o conjunto de setores e ramos produtivos da economia nacional" (AMORIM FILHO; SERRA, 2001, p. 23).

Porém, o avanço das técnicas amplia também o papel das metrópoles, considerando este um espaço adequado para a consolidação das atividades econômicas modernas, visto que nelas estão a maior concentração de universidades, centros de pesquisa, etc. Em um movimento paradoxal de ascensão das cidades médias e revalorização das metrópoles, a 
rede urbana brasileira pós-fordista foi sintetizada como um movimento contraditório que se observa

de um lado, uma tendência à reconcentração espacial, particularmente ligada aos imperativos da acumulação financeira internacional, à organização de alguns setores internacionais e à qualidade dos mercados do trabalho, como demonstra a participação da metrópole de São Paulo no conjunto das atividades econômicas do estado e do país ,ou seja, verifica-se que a aglomeração espacial ainda apresenta vantagens ao reduzir custos de transações e aumentar externalidades positivas; nessa direção, no tocante à atividade produtiva, observa-se que a grande metrópole ainda exerce fator de atração de novos e modernos investimentos, como demonstram os pólos de alta tecnologia em torno de Los Angeles, e mesmo a participação de São Paulo no conjunto de atividades de maior intensidade de tecnologia do país (...). Ao mesmo tempo, observa-se ainda, de outro lado, o desenvolvimento rápido de centros urbanos intermediários, cujo crescimento está crescentemente relacionado aos circuitos do capitalismo mundial, como, por exemplo, as cidades da chamada Terceira Itália, assim como novas áreas de atração industrial no Estado do Paraná, além dos diversos centros médios de crescimento acima da média nacional que a presente pesquisa verificou. [IPEA/IBGE/Nesur-IEUnicamp (1999, p. 62-63].

A abertura comercial proporcionou maior dinamismo entre as trocas de insumos produtivos e comercialização de produtos finais, estando as regiões em um contexto de abertura comercial mais favorecidas com o barateamento de insumos e produtos. No Brasil, este fato foi observado, principalmente, em pontos do centro-sul do país, aumentando as disparidades regionais e limitando a desconcentração produtiva apenas à área economicamente mais dinâmica (AMORIM FILHO; SERRA, 2001, p. 25).

A diminuição no papel do Estado nas políticas de planejamento, por sua vez, levanta hipóteses acerca da desconcentração concentrada, principalmente devido a também redução do papel efetivo do Estado no desenvolvimento econômico nacional. As políticas de privatização associam-se a concentração urbana quando associadas a perda de capacidade de investimento estatal direto. Os investimentos privados em infraestrutura tendem a se vincular ao princípio da eficiência e maior lucratividade, canalizando os efeitos em áreas de maior dinamismo econômico ao invés de priorizar a equidade na distribuição socioespacial de capital fixo, aumentando as diferenças de produtividade inter-regionais (AZZONI; FERREIRA, 1997). Somado a isto, as políticas de planejamento regional perdem status, não figurando entre os principais planos do Governo.

Isto posto, os mecanismos da década de 1990 ampliaram os papéis das cidades médias, sobretudo, as localizadas na região brasileira mais abastada, em função do dinamismo econômico e por elas [as cidades médias] serem fundamentais para a "manutenção do sistema socioeconômico vigente (...) e representam válvulas de desconcentração que conseguem diminuir o mau funcionamento do sistema capitalista" (AMORIM FILHO; SERRA, 2001, p. 19).

Desde então, as cidades médias apresentam-se enquanto importantes nós na rede urbana brasileira por evoluir junto ao sistema capitalista e comandar uma produção regional em seus aspectos técnicos e, principalmente, por difundir a produção e o consumo para toda a sua hinterlândia, sendo reconhecidas principalmente enquanto lócus da circulação capitalista mais do que da produção propriamente dita. 


\section{CONSIDERAÇÕES FINAIS}

69 A partir das mudanças no padrão de acumulação do sistema capitalista o espaço urbano também se reconfigurou, tanto na escala da cidade quanto da rede urbana, emergindo novas formas e funções.

70 O sistema fordista, marcado pelas produções em massa, demandava aglomerações urbanas e econômicas em função da sua organização produtiva de caráter bem rígido. Além disso, contava com o apoio de um grande Estado que desempenhava as funções de provedor dos bens coletivos e de uma mão de obra altamente organizada. Com o declínio do Estado de bem estar social e a recessão econômica da década de 1970, além da flexibilização dos mercados japoneses e coreanos no setor automotivo, levou a crise do sistema.

71 Isto posto, o padrão de acumulação flexível emerge enquanto alternativa a rigidez fordista. É marcado por uma lógica just in time, sem estocagens e grandes produções em massa para atender um consumo cada vez mais especializado. Devido a isso, dentre outros fatores, como abertura do mercado e interiorização da produção, a produção do espaço urbano durante este período também sofre alterações, apresentando uma lógica também mais flexível e tornando a rede urbana mais complexa em detrimento a rede macrocefálica fordista.

72 Em linhas gerais, a emergência de um novo padrão de acumulação engendra reestruturações em todo o espaço, sobretudo, no espaço das cidades, uma vez que a urbanização é uma das facetas do capitalismo e a cidade é o lócus da produção, além de ser onde o lucro se realiza mais facilmente.

\section{BIBLIOGRAPHY}

AMORIM FILHO, O. B. Cidades médias e organização do espaço no Brasil. Geografia e Ensino, Belo Horizonte, ano II, n. 5, p. 5-34, jun.1984.

AMORIM FILHO, O.; SERRA, R. V. Evolução e perspectivas do papel das cidades médias no planejamento urbano e regional. In: ANDRADE, T. A.; SERRA, R. V. (org.) Cidades médias brasileiras. Rio de Janeiro: IPEA, 2001. p.1-34.

ANDRADE, T. A.; SERRA, R. V. O desempenho das cidades médias no crescimento populacional brasileiro no período 1970/2000. In: ANDRADE, T. A.; SERRA, R. V. (org.) Cidades médias brasileiras. Rio de Janeiro: IPEA, 2001. p.129-169.

AZZONI, C. R., FERREIRA, D. Competitividade regional e reconcentração industrial: o futuro das desigualdades regionais no Brasil. Rio de Janeiro: Nemesis/Pronex, 1997 (Relatório).

BESSA, K. C. Reestruturação da rede urbana brasileira e cidades médias: o exemplo de Uberlândia (MG). Caminhos de Geografia. V. 24, N. 16, pp. 168-188, 2005.

BRASIL. II Plano Nacional de Desenvolvimento 1975/79. Distrito Federal, 1974. 
BRENNER, N. Between fixity and motion: accumulation, territorial organization and the historical geography of spatial scales. Envlroment and Planning D: Society and Space, 1998, v. 16, PP. 459-481.

CASTELLS, M. A questão urbana. 4. ed. Rio de Janeiro: Paz e Terra, 1983.

CHESNAIS, F. Mundialização: o capital financeiro no comando. Les Temps Modernes. 607, 2000. Disponível em http://outubrorevista.com.br/wp-content/uploads/2015/02/Revista-OutubroEdic\%CC\%A7a\%CC\%83o-5-Artigo-02.pdf.

CORREA, R. L. A rede urbana brasileira e a sua dinâmica: algumas reflexões e questões. In: SPÓSITO, M. E. B. (org.). Urbanização e cidades: perspectivas geográficas. Presidente Prudente: [s.n.], 2001. p.359-367.

Reflexões sobre a dinâmica recente da rede urbana brasileira. ENCONTRO NACIONAL DA ANPUR, IX, 2001, Rio de Janeiro. Anais... Rio de Janeiro: ANPUR, vol. 1, 2001a. p.424-430.

Estudos sobre a rede urbana. Rio de Janeiro: Bertrand Brasil, 2006.

FERRARI, T. Fabricalização da Cidade e Ideologia da Circulação. São Paulo: Terceira Margem, 2005.

GOMES, M. T. S. O debate sobre a reestruturação produtiva no Brasil. RA'EGA, 2011, pp. 51-77.

GOHN, M. G. Reivindicações populares urbanas. São Paulo: Cortez, 1982

GOTTDIENER, M. A produção social do espaço urbano. São Paulo: EDUSP,1993.

HARVEY, D. Condição pós-moderna. São Paulo: Edições Loyola, 1992. 349 p.

IPEA/IBGE/NESUR-IE-UNICAMP. Caracterização e tendências da rede urbana do Brasil.

Campinas, São Paulo: Unicamp/IE, 2 v, 1999 (Coleção Pesquisas, 3).

LEFEBVRE, H. A produção do espaço. Tradução do grupo “As impossibilidades do urbano na metrópole contemporânea”, UFMG: Belo Horizonte, 2006 [1972].

MARTINS, J. S. Sobre o modo capitalista de pensar. São Paulo: Hucitec, 1982.

SANTOS, M. Por uma Geografia Nova. São Paulo: Hucitec, 1978.

Técnica, espaço, tempo: globalização e meio técnico-científico-informacional. São Paulo: Hucitec, 1994.

SMITH, N. Desenvolvimento desigual: natureza, capital e a produção de espaço. Trad.: Eduardo De Almeida Navarro. Rio de Janeiro: Bertrand Brasil, 1988.

SPOSITO, M. E. B. As cidades médias e os contextos econômicos contemporâneos. In: (org.). Urbanização e cidades: perspectivas geográficas. Presidente Prudente: [s.n.], 2001. p.609-643.

O chão em pedaços: urbanização, economia e cidades. Tese (Livre Docência) Faculdade de Ciência e Tecnologia. Universidade Estadual Paulista, Presidente Prudente, 508 p, 2004.

\section{ABSTRACTS}

The modes of capitalist production have always had a very important spatial dimension, since the production of space is inherent to capitalist reproduction. In this direction, space has always reflected the cycles and maneuvers of capital, considering that it is essential for the maintenance of the system. As the patterns of accumulation change, the city and region spaces also undergo 
restructuring, meeting the demands of the process. Thus, the work that follows seeks to emphasize the differences between the modes of Fordist accumulation and flexible accumulation, as well as their brands in cities and in the Brazilian urban network

Os modos de produção capitalista sempre tiveram uma vertente espacial muito importante, uma vez que a produção do espaço é inerente a reprodução capitalista. Nesta direção, o espaço sempre refletiu os ciclos e manobras do capital, considerando que ele é essencial para a manutenção do sistema. À medida que os padrões de acumulação sofrem alterações, os espaços da cidade e da região também passam por reestruturações, atendendo as demandas do processo. Isto posto, o trabalho que segue busca salientar as diferenças entre os modos de acumulação fordista e acumulação flexível, bem como as suas marcas nas cidades e na rede urbana brasileira.

Les modes de production capitaliste ont toujours eu une dimension spatiale très importante, car la production d'espace est inhérente à la reproduction capitaliste. Dans cette direction, l'espace a toujours reflété les cycles et les manœuvres du capital, estimant qu'il est essentiel pour la maintenance du système. À mesure que les modèles d'accumulation changent, les espaces urbains et régionaux subissent également une restructuration, répondant aux exigences du processus. Ainsi, le travail qui suit cherche à souligner les différences entre les modes d'accumulation fordiste et d'accumulation flexible, ainsi que leurs marques dans les villes et le réseau urbain brésilien.

Los modos de producción capitalista siempre tuvieron una vertiente espacial muy importante, ya que la producción del espacio es inherente a la reproducción capitalista. En esta dirección, el espacio siempre reflejó los ciclos y maniobras del capital, considerando que es esencial para el mantenimiento del sistema. A medida que los patrones de acumulación sufren cambios, los espacios de la ciudad y de la región también pasan por reestructuraciones, atendiendo a las demandas del proceso. Esto puesto, el trabajo que sigue busca resaltar las diferencias entre los modos de acumulación fordista y acumulación flexible, así como sus marcas en las ciudades y en la red urbana brasileña.

\section{INDEX}

Mots-clés: Fordisme ; Accumulation Flexible ; Production de l'espace urbain.

Palabras claves: Fordismo; Acumulación Flexible; Producción del espacio urbano.

Palavras-chave: Fordismo; Acumulação Flexível; Produção do Espaço Urbano.

Keywords: Fordism; Flexible Accumulation; Production of urban space.

\section{AUTHOR}

\section{SAMARANE FONSECA DE SOUZA BARROS}

Universidade Federal de Juiz de Fora

Programa de Pós Graduação em Geografia

Bolsista CAPES

samaraneb@gmail.com 